\title{
KAWASAKI DISEASE: A CASE REPORT
}

\author{
Shiv Dinesh Dyarapogu ${ }^{1}$ \\ ${ }^{1}$ PharmD, \\ Pullareddy Institute of Pharmacy, \\ Hyderabad, \\ Telangana.
}

\author{
Safi Ur-Rahman Mohammed ${ }^{3}$ \\ ${ }^{3}$ (PharmD), \\ Sultan-ul-Uloom college of pharmacy, \\ Hyderabad, \\ Telangana.
}

\author{
Abdul Mustaq Mohammed ${ }^{2}$ \\ ${ }^{2}$ (PharmD), \\ Sultan-ul-Uloom College of pharmacy, \\ Hyderabad, \\ Telangana
}

\author{
Muneb Ahmed ${ }^{4}$ \\ ${ }^{4}$ (PharmD), \\ Sultan-ul-Uloom College of pharmacy, \\ Hyderabad, \\ Telangana
}

\author{
Dr. S P Srinivas Nayak ${ }^{5}$ * \\ ${ }^{* 5}$ Assistant professor, \\ Department of Pharmacy Practice \\ Sultan-ul-Uloom College of pharmacy, \\ Hyderabad, \\ Telangana. \\ ORCID ID: 0000-0003-1729-7587,
}

Article DOI: https://doi.org/10.36713/epra5181

\begin{abstract}
Kawasaki disease (KD) is a systemic vasculitis mostly affecting medium-sized arteries. Main symptoms include fever, conjunctivitis, skin and mucous membrane affection, and cervical lymphadenopahty. KD begins with acute-onset high fever, reduced general condition and frequently reduced cooperativity of children which can complicate physical examination. Further symptoms include generalized polymorphic exanthema (>90\%), palmoplantar erythema (80\%), symmetric non purulent conjunctivitis (80-90\%), usually unilateral cervical lymphadenopathy (>1.5 cm; 50\%), and mucosal enanthema with red and/or chapped lips (80-90\%). A female patient of 8 months and weight 10.2kg was bought to the hospital on 17/1/2020 with the complaints of prolonged high grade fever since last 10 days, previously the baby was treated with antibiotics but the fever was not subsided. On further evaluation the child was diagnosed with KD and symptomatic treatment given along with standard immunoglobulin and aspirin. Patient was treated well and discharged.
\end{abstract}

KEYWORDS: Kawasaki, medium sized articles, chapped lips, fever 


\section{INTRODUCTION}

Kawasaki disease(KD) is a systemic vasculitis mostly affecting medium-sized arteries. Main symptoms include fever, conjunctivitis, skin and mucous membrane affection, and cervical lymphadenopathy. The name KD goes back to the detailed description of 50 children experiencing this form of vasculitis by Tomakisu Kawasaki in 1967[1]. The prevalence of KD is higher in Asian countries than in western countries. Japan has the highest annual incidence rate, followed by Korea and Taiwan, and the lowest rate is seen in Europe[2][3]. Generally, inflammatory changes to arterial vessels of all body regions can be present, however, coronary arteries are most commonly affected [4]. The most serious complication of $\mathrm{KD}$ is the involvement of coronary artery lesions (CAL), including myocardial infarction, coronary artery fistula formation, coronary artery dilatation and coronary artery aneurysm[5][6]. The severe complication of KD is the occurrence of CAL and this often occurs in the sub-acute phase [7]. There is a $15-25 \%$ incidence of CAL developing in $\mathrm{KD}$ patients without early treatment[8]. It is also the leading cause of acquired heart disease in children. [9] If the aneurysm persists and becomes occlusive, it may increase the risk of myocardial infarction or sudden death [10][11]. In cases of delayed treatment, missed diagnosis, or in treatment refractory cases, aneurysms can result and cause severe sequelae, including cardiac infarctions (Figure 1).Globally, $\mathrm{KD}$ is the most common primary childhood vasculitis, in central Europe and North America it is the second most common form Henoch Schoenlein Purpura (HSP). To date, $\mathrm{KD}$ is considered the most common acquired cardiac condition in childhood in developed countries [12][13].

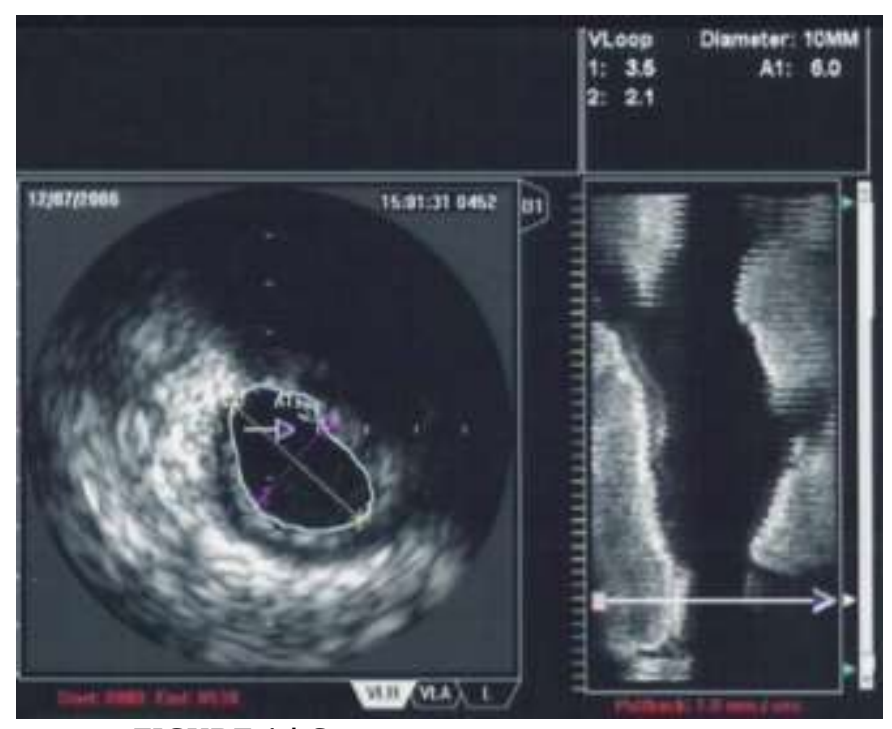

FIGURE 1 | Coronary artery aneurysms

KD begins with acute-onset high fever, reduced general condition and frequently reduced cooperativity of children which can complicate physical examination. Further symptoms include generalized polymorphic exanthema (>90\%), palmoplantar erythema $(80 \%)$, symmetric non purulent conjunctivitis (80-90\%), usually unilateral cervical lymphadenopathy $(>1.5 \mathrm{~cm}$;
$50 \%$ ), and mucosal enanthema with red and/or chapped lips (80-90\%) [14] (Figure 2). Additional symptoms include anterior uveitis that can occur in up to $80 \%$ of patients [15], and arthritis of small joints (in up to 15\%) [16]. Later, after several weeks, periungual and/or perianal desquamation, and nail anomalies (Beau lines) can occur[17]. 


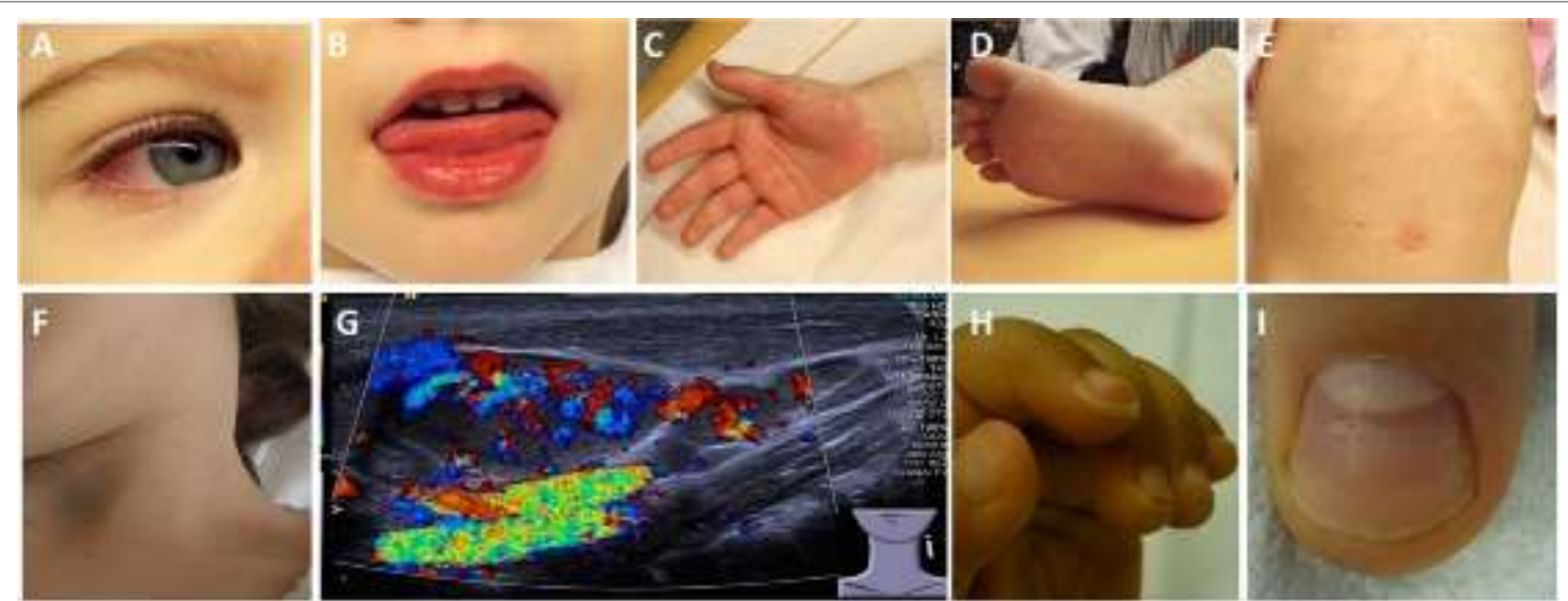

FIGURE 2 | Clinical criteria in KD. (A) Bilateral non-purulent conjunctivitis (80-90\%), (B) changes to oropharyngeal mucous membranes, including injected and/or fissured lips, strawberry tongue (80-90\%), (C) Palmar and/or (D) plantar erythema (E) polymorphous exanthema, primarily truncal, not vesicular $(>90 \%)$, and $(F$,

G) cervical lymphadenopathy $(>1.5 \mathrm{~cm})(50 \%)$. (G) Ultrasound of enlarged cervical lymph nodes with increased perfusion. (H) Periungual desquamation (in covalescent phase) (80\%), (I) Beau lines. [21]

\section{CASE REPORT}

A female patient of 8 months and weight 10.2 $\mathrm{kg}$ was brought to the hospital on $17 / 1 / 2020$ with the complaints of prolong high grade fever since last 10 days, previously the baby was treated with Piperacillin, Amikacin and Syp. Azithromycin but the fever was not subsided. So, the patient got discharged, came to our hospital for further management. On examination the patient was found to have high grade fever $\left(101^{\circ} \mathrm{F}\right)$ with non-purulent conjunctivitis, cracked fissured lips, redness of skin(ankles and hand ) enanthema and cherry tounge. SPo2 was found to be $98 \%$, Heart rate 100bpm, CVS - S1 S2 +ve, CBP showed thrombocytosis, CRP - 4.26(increased), patient was positively reactive to $\mathrm{BCG}$, the culture test showed negative result, the echocardiography showed dilated coronary arteries (coronary aneurysm) and the patient is finally diagnosed with Kawasaki disease.

SERELOGICAL REPORT

\begin{tabular}{|c|c|c|c|c|}
\hline TEST & Day1 & Day2 & Day3 & Day4 \\
\hline C-reactive Protein & $4.3 \mathrm{mg} / \mathrm{dl}$ & $1.31 \mathrm{mg} / \mathrm{dl}$ & $0.82 \mathrm{mg} / \mathrm{dl}$ & $0.53 \mathrm{mg} / \mathrm{dl}$ \\
\hline
\end{tabular}

\begin{tabular}{|c|c|c|}
\hline \multicolumn{1}{|c|}{ COMPLETE BLOOD COUNT } \\
\hline TEST & RESULT & NORMAL VALUES \\
\hline 1. Haemoglobin(Hb) & $10.5 \%$ & $12.0-17.0 \%$ \\
\hline 2. RBC Count & $5.3 \%$ & $4.6-6 . \%$ \\
\hline 3. WBC Count & 25,000 cells $/ \mathrm{cumm}$ & $4000-11000 \mathrm{cells} / \mathrm{cumm}$ \\
\hline 4. Platelets Count & 8lakhs $/ \mathrm{cumm}$ & $1.5-4.5 \mathrm{lakhs} / \mathrm{cumm}$ \\
\hline
\end{tabular}

\section{OTHER RELEVANT TESTS}

Erythrocytes Sedimentation Rate - $63 \mathrm{~mm}$ at the end of 1 hour (Norma: 13-20mm/hour), Throat Swab Culture- was found to be sterile. Urine culture examination - was found to be negative. No microbial infection was reported. 2D Echo - Cardiography Coronary Aneurysm (also bilateral dilated coronary arteries) 
DRUGS PRESCRIBED

DAY 1 and 2.

\begin{tabular}{|c|c|c|c|c|}
\hline S.No & DRUG & DOSE & FREQUENCY & $\begin{array}{c}\text { ROUTE OF } \\
\text { ADMINISTRATION }\end{array}$ \\
\hline 1. & $\begin{array}{c}1 / 2 \text { Dextrose Normal Saline + Aluminium } \\
\text { Hydroxide+Magnesium } \\
\text { Hydroxide+Dimethicone }\end{array}$ & $200 \mathrm{ml}$ & TID & IVF \\
\hline 2. & Inj. CEFOTAXIME & $500 \mathrm{mg}$ & BID & IVF \\
\hline 3. & SYP. PARACETAMOL & $250 \mathrm{mg}$ & $3 \mathrm{ml}($ SOS)if fever & $\mathrm{P} / 0$ \\
\hline 4. & TAB. ASPIRIN & $325 \mathrm{mg}$ & TID $(1-1-1 / 4)$ & $\mathrm{P} / 0$ \\
\hline 5. & SYP .RANITIDINE & $3 \mathrm{ml}$ & bid before breakfast & IV \\
\hline 6. & Inj. IMMUNOGLOBULIN & $20 \mathrm{mg}$ & BID every 12 hours & \\
\hline
\end{tabular}

DAY 3, 4 and 5.

\begin{tabular}{|c|c|c|c|c|}
\hline S.NO & DRUG & DOSE & FREQUENCY & $\begin{array}{c}\text { ROUTE OF } \\
\text { ADMINISTRATION }\end{array}$ \\
\hline 1. & SYP. CEFOTAXIME & $50 \mathrm{mg}$ & $5 \mathrm{ml}$ BID & $\mathrm{P} / 0$ \\
\hline 2. & SYP. PARACETAMOL & $250 \mathrm{mg}$ & $3 \mathrm{ml}($ SOS)if fever & P/O \\
\hline 3. & TAB. ASPIRIN & $325 \mathrm{mg}$ & TID(1-1-1/4) & $\mathrm{P} / 0$ \\
\hline 4. & SYP. RANITIDINE & $3 \mathrm{ml}$ & bid before breakfast & P/O \\
\hline 5. & SYP. VITNEURIN & $5 \mathrm{ml}$ & OD & $\mathrm{P} / 0$ \\
\hline 6. & SYP. CALINTA & $5 \mathrm{ml}$ & OD & \\
\hline
\end{tabular}

*Syrup VITENURIN contains BIOTIN+CHOLINE+CYNOCOBALAMINE+D-PANTHENOL+ELEMENTAL

ZINC+FOLIC ACID+ INOSITOL+NIACINAMIDE+PYRIDOXINE+RIBOFLAVINE+THIAMINE+VITAMIN

A+VITAMIN D+VITAMIN E

* Syrup CALINTA contains CALCIUM CARBONATE+CALCITRIOL+ZINC SULFATE

DISCHARGE MEDICATIONS

\begin{tabular}{|c|c|c|c|c|}
\hline S.NO & DRUG NAME & DOSE & FREQUENCY & $\begin{array}{c}\text { ROUTE OF } \\
\text { ADMINISTRATION }\end{array}$ \\
\hline 1. & SYP. CEFOTAXIME & $50 \mathrm{mg}$ & $5 \mathrm{ml}$ BID 6days & $\mathrm{P} / 0$ \\
\hline 2. & SYP. PARACETAMOL & $250 \mathrm{mg}$ & $3 \mathrm{ml}($ sis)if fever & $\mathrm{P} / 0$ \\
\hline 3. & TAB. ASPIRIN & $325 \mathrm{mg}$ & 7days TID(1-1-1/4) & $\mathrm{P} / 0$ \\
\hline 4. & SYP. RANITIDINE & $3 \mathrm{ml}$ & bid before breakfast for 10 days & $\mathrm{P} / 0$ \\
\hline 5. & SYP. VITNEURIN & $5 \mathrm{ml}$ & 30 days & $\mathrm{P} / 0$ \\
\hline 6. & SYP. CALINTA & $5 \mathrm{ml}$ & 30days & $\mathrm{P} / 0$ \\
\hline
\end{tabular}

*Syrup VITENURIN- BIOTIN+CHOLINE+CYNOCOBALAMINE+D-PANTHENOL+ELEMENTAL ZINC+FOLIC

ACID+ INOSITOL+NIACINAMIDE+PYRIDOXINE+RIBOFLAVINE+THIAMINE+VITAMIN A+VITAMIN

D+VITAMIN E

* Syrup CALINTA-CALCIUM CARBONATE+CALCITRIOL+ZINC SULFATE

\section{DISCUSSION}

Kawasaki disease is the second most common cause of vasculitis in children after Henoch Schonlein purpura[19,20].

On physical examination the patient was found with prolong high grade fever with non-purulent conjunctivitis, cracked fissured lips, redness of skin(ankles and hand) enanthema and cherry tounge. In a study conducted by Pei-Shin Chen et al entitled Clinical manifestations of Kawasaki disease shock syndrome: A case control study and Abdullah Al Saleh's Kawasaki Disease: A case study, these all clinical features were found to be same. The blood sample was collected for Complete Blood Picture(CBP) Examination, the results were found as Haemoglobin10.5\%, Red Blood Cells Count - 5.3\%, White Blood Cells Count- 25,000 cells/cumm, Platelets count8lakhs/cum, Neutrophils $72 \%$ and Erythrocytes Sedimentation Rate(ESR) - $63 \mathrm{~mm}$ at the end of 1 hour (13-20mm/hour). Which represented as Leukocytosis, 
Neutrophilia, Thrombocytosis and increased ESR. In a study conducted by Christian M. Hedrich's et al Kawasaki Disease and Abdullah Al Saleh's Kawasaki Disease: A case study, similar abnormal CBP results were found. The sereological test of C-Reactive Protein(CRP) was performed on daily basis, the results obtained was on day $1-4.32 \mathrm{mg} / \mathrm{dl}$, day2- $1.31 \mathrm{mg} / \mathrm{dl}$, day3 - 0.73mg/dl and day4 - 0.53mg/dl. The CRP levels on day1 was found to be elevated. In a study conducted by Christian M. Hedrich's et al entitledKawasaki Disease and Abdullah Al Saleh's Kawasaki Disease: A case study, the same elevated CRP results were noted in their patient case report. The culture test was also performed to detect microbial infection via throat culture swab and Urine culture examination. The throat culture swab examination was found to be sterile. The urine culture examination was also performed which resulted negative, which confirmed no presence of infection. In a study conducted by Abdullah Al Saleh's Entitled-Kawasaki Disease: A case study, the above culture sensitive test results was same in that patient case report. 2D Echo cardiography was performed, it resulted in Coronary Aneurysm (also bilateral dilated coronary arteries). The same result was found in a study conducted by Karen Texters et al, Case Study: Kawasaki Disease, patient case report. Based on above clinical features and investigational reports, it was finally confirmed the patient was suffering from KD. The patient was suggested to ImmunoGlobulin and anti-coagulant therapy. In a study conducted by Karen Texter's et al, Entitled-Case Study: Kawasaki Disease and Abdullah Al Saleh's Entitled - Kawasaki Disease: A case study, the suggested therapy was found the same. On dayl The patient was assisted to Oxygenation therapy and Intravenously infused with $1 / 2$ Dextrose Normal Saline + Aluminium Hydroxide + Magnesium Hydroxide + Dimethicone. Injection Immunoglobulin(IG) $20 \mathrm{mg} / \mathrm{ml}$ thrice a day and Antibiotic Injection Cefotaxime $500 \mathrm{mg} / \mathrm{ml}$ Twice a day was prescribed and administered immediately. Syrup paracetamol 250mg, $3 \mathrm{ml}$ as required, Tablet Aspirin $325 \mathrm{mg}$ for 7Days Thrice a day and syrup Ranitidine $3 \mathrm{ml}$ before breakfast for 10 days twice a day was prescribed. On day 3 IVF DNS, Injection Cefotaxime and Injection Immunoglobulin was stopped. Syrup Cefotaxime $50 \mathrm{mg}$ twice a day $5 \mathrm{ml}$ for 6 days, syp. Biotin + choline + cynocobalamine $+\mathrm{d}$-panthenol + elemental zinc + folic acid + inositol + niacinamide + pyridoxine + riboflavin + thiamine + vitamin $\mathrm{A}+$ vitamin $\mathrm{D}+$ vitamin $\mathrm{E} 5 \mathrm{ml}$ for 30 days and syp. calcium carbonate + calcitrio + zinc sulfate $5 \mathrm{ml}$ for 30 days was prescribed and continued. On day 5 the patient was stable and the same medications were prescribed as discharge medications. The patient was completely stabilized and escorted back to her home. The patient was maintained with the same dosage of aspirin for one week, then the dose was reduced to $(5 \mathrm{mg} / \mathrm{kg} /$ day $)$ for the next 6 weeks.

\section{CONCLUSION}

Kawasaki is a rare terrifying vasculitis in children. Fever lasting with more than a week, skin rashes, cracked lips, lymph adenopathy, non-purulent conjunctivitis and abnormal lab investigations are main clinical presentations. Early detection and diagnosis wirh immediate immunoglobulin and aspirin therapy can save patient from severe complications. Our case was handled with KD and basic symptomatic treatment given along with standard immunoglobulin and aspirin. The patient was stabilized and recovered from the symptoms. Discharged with basic multivitamins, aspirin and paracetamol when ever necessary. If patients suffers from chicken pox, mumps, measles then aspirin Should be discontinued. MMR, Varicella, OPV vaccinations are avoided for a year.

\section{REFERENCES}

1. Kawasaki T. [Acute febrile mucocutaneous syndrome with lymphoidinvolvement with specific desquamation of the fingers and toes in children].Arerugi (1967) 16:178-222.

2. Mandal S, Pande A, Mandal D, Sarkar A, Kahali D, Panja M.Various coronary artery complications of Kawasaki disease:series of 5 cases and review of literature. J Cardiovasc Dis Res2012;3:231-5.

3. Huang WC, Huang LM, Chang IS, Chang LY, Chiang BL, Chen PJ,et al. Epidemiologic features of Kawasaki disease in Taiwan,2003-2006. Pediatrics 2009;123:-401-5.

4. Naoe S, Takahashi K, Masuda H, Tanaka N. Kawasaki disease. Withparticular emphasis on arterial lesions. Acta Pathol Japonica (1991) 41:785-97.doi: 1827.1991.tb01620.x

5. Liang $C D$, Kuo HC, Yang KD, Wang CL, Ko SF. Coronary arteryfistula associated with Kawasaki disease. Am Heart J 2009; 157:584-8.

6. Newburger JW, Takahashi M, Gerber MA, et al. Diagnosis,treatment, and long-term management of Kawasaki disease:a statement for health professionals from the Committee onrheumatic fever, endocarditis and kawasaki disease, Councilon cardiovascular disease in the young, American Heart Association.Circulation 2004;110:2747-71.

7. Kuo $H C$, Liang $C D$, Wang $C L, Y u H R$, Hwang $K P$, Yang KD. Serum albumin level predicts initial intravenous immunoglobulin treatment failure in Kawasaki disease. Acta Paediatr 2010;99: 157883.a 
8. Burns JC, Glode' MP. Kawasaki syndrome. Lancet 2004;364:533-44.

9. Wang CL, Wu YT, Liu CA, Kuo HC, Yang KD. Kawasaki disease:infection, immunity and genetics. Pediatr Infect Dis J 2005;24:998-1004.

10. Mandal S, Pande A, Mandal D, Sarkar A, Kahali D, Panja M.Various coronary artery complications of Kawasaki disease:series of 5 cases and review of literature. J Cardiovasc Dis Res 2012;3:231-5.

11. Suzuki A, Kamiya T. Visualization of coronary artery lesions inKawasaki disease by coronary angiography. Cardiol Young1991;1:225-33.

12. Weiss PF Pediatric vasculitis. Pediatr Clin North Am. (2012) 59:407-23. doi: 10.1016/j.pcl.2012.03.013

13. McCrindle BW, Rowley AH, Newburger JW, Burns $J C$, Bolger AF, Gewitz $M$, et al. Diagnosis, treatment, and long-term management of Kawasaki disease: a scientific statement for health professionalsfrom the American heart association. Circulation (2017) 135:927-99.doi: 10.1161/CIR.0000000000000484

14. Burns JC, Mason WH, Glode MP, Shulman ST, Melish ME, Meissner $C$, et al. Clinical and epidemiologic characteristics of patients referred for evaluation of possible Kawasaki disease. United States Multicenter Kawasaki Disease Study Group. J Pediatr. (1991) 118:680-6. doi: 10.1016/S00223476(05)80026-5

15. Burns JC, Joffe L, Sargent RA, Glode MP. Anterior uveitis associated with Kawasaki syndrome. Pediatr Infect Dis. (1985) 4:258-61. doi: 10.1097/00006454-198505000-00010

16. Baker AL, Lu M, Minich LL, Atz AM, Klein GL, Korsin R, et al. Associated symptoms in the ten days before diagnosis of Kawasaki disease. J pediatr. (2009) 154:592-5-2. doi: 10.1016/j.jpeds.2008.10.006

17. Wang S, Best BM, Burns JC. Periungual desquamation in patients with Kawasaki disease. Pediatr Infect Dis J. (2009) 28:538-9. doi: 10.1097/INF.0b013e3181945984

18. SonMBSRP. Kawasaki disease. In: Petty RELRMLCBWLR editor. Textbook of Pediatric Rheumatology, Vol. 7. Philadelphia, PA: Elsevier (2016). p. 467-83.

19. Melish ME, Hicks RV. Kawasaki syndrome: clinical features, pathophysiology, etiology Rheumatol Suppl. 1990;24:2-10.

20. Dhillon $R$, Newton L, Rudd PT, Hall SM. Management of Kawasaki disease in the British Isles. Arch Dis Child. 1993;69:631-8

21. Christian M. Hedrich et al,Kawasaki Disease,Frontiers in pediatrics, 10 July 2018, Volume 6, Article 198,p.1-10. 